\title{
Espacios recíprocos: sinergias entre antropología social y arquitectura. Herramientas para el análisis del verde urbano y el espacio público
}

Synergies Between Social Anthropology and Architecture. Analysing Urban Green and Public Spaces

\section{Waltraud Müllauer-Seichter ${ }^{*}$}

(iD) https://orcid.org/0000-0003-1098-0375

Tipo de Artículo: Informes de Investigación y ensayos inéditos

Doi: 10.17533/udea.unipluri.20.2.02

Müllauer-Seichter, W. (2020). Espacios recíprocos: sinergias entre antropología social y arquitectura. Herramientas para el análisis del verde urbano y el espacio público. Uni-Pluriversidad, 20(2), e2020202. doi:

10.17533/udea.unipluri.20.2.02

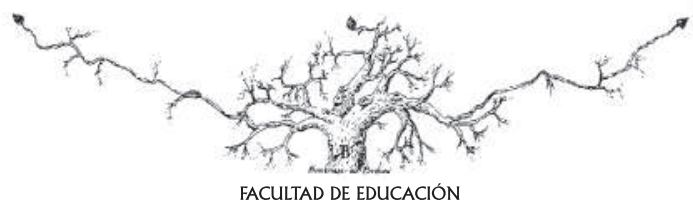

Recibido: 2019-07-16 • Aprobado: 2020-07-12

* Universidad Nacional de Educación a Distancia. España Email: wmullauer@fsof.uned.es 


\title{
Resumen
}

El ensayo se centra en las experiencias de investigación antropológica desarrolladas en los últimos veinte años en diferentes ámbitos geográficos de Europa y América Latina, sobre el espacio verde, el espacio público urbano, el alcance de la participación ciudadana respecto a la toma de decisiones sobre el entorno vital y, finalmente, sobre el derecho legítimo de la opinión de los niños dentro de la modificación de espacios lúdicos. Tras la ejecución de diversos proyectos $\mathrm{I}+\mathrm{D}+\mathrm{I}$ de investigación, la combinación de técnicas y herramientas prestadas de disciplinas afines se analiza con la finalidad de indagar en la calidad de vida, el entorno vital y la percepción de las personas para explorar con éxito cuestiones sobre las convergencias en el espacio y el tiempo, las velocidades y las temporalidades de la ciudad. La idoneidad del uso de estas técnicas se refleja en la aplicación práctica en el marco del Máster en Educación Intercultural que lleva a cabo la Universidad Nacional de Educación a Distancia (UNED, España) con la Universidad Veracruzana (UV, México) y del Máster Universitario en Formación del Profesorado de Educación Secundaria de Ecuador

Palabras clave: Participación Ciudadana, Antropología Urbana, Formación del profesorado, Educación Secundaria, Educación Superior.

\begin{abstract}
This interdisciplinary approach has been successfully implemented in the author's several financed ethnographic research experiences in which people's own perceptions, quality of life, and time and spatial scales in their use and enjoyment of urban green areas and citizen participation have been addressed. After reviewing most research European and Latin-American studies in this field, it is also claimed that children's decision rights on implementation and/or modification of recreational areas should also be considered. Results of these investigations have been incorporated in different publications as well as in teaching materials in several post graduate courses and programmes, both in Spain (UNED) and in Latin America (Universidad Veracruzana, México; Secondary Education Teacher Training, Ecuador).
\end{abstract}

Keywords: Citizen Participation, Urban Anthropology, Teacher Training, Secondary Education, Higher Education. 


\section{A MOdo DE INTRODUCCIóN}

En este texto se ofrece una serie de técnicas y herramientas prestadas de diferentes disciplinas de las Ciencias Sociales y de la Arquitectura para explorar el valor social del espacio público y el espacio verde en la ciudad. Se analiza de forma individual el grado de información que puede aportar cada herramienta tras su aplicación en varios proyectos y se cuestiona su idoneidad como recurso adicional a la investigación en Antropología Social.

Aparte de la discusión sobre el tool-kit, su utilidad y el grado de esfuerzo justificado en investigaciones concretas, el texto invita a analizar la combinación de las lógicas metodológicas en Arquitectura y Antropología Urbana, por un lado, como herramientas útiles para su aplicación en disciplinas afines que tienen como preocupación compartida indagar en la calidad de vida, el entorno vital y la percepción de las personas para explorar con éxito cuestiones sobre las convergencias en el espacio y el tiempo, las velocidades y las temporalidades de la ciudad. Como se verá a lo largo del trabajo, la combinación de las herramientas y técnicas del pool aquí mencionadas dependen necesariamente del tema de investigación. Por tanto, cada investigación exige su propia composición para llegar más allá de los posibles resultados adquiridos mediante los enfoques de la metodología propia de ambas disciplinas. También hay que sopesar el esfuerzo y el tiempo invertido en relación con la información adicional adquirida. Por otro lado, a lo largo de estos años, se ha perfilado y aplicado el tool-kit en el campo de la Educación entre 2006 y 2013 dentro del marco de los proyectos I+D "Estrategias de investigación social de racismo en las escue- las I y II", financiados por el Ministerio de Educación de España.

La idoneidad de las técnicas se analiza tras su aplicación en los siguientes proyectos de investigación. El primero se centra en los resultados obtenidos en los estudios realizados en la Casa de Campo (Madrid). El segundo se centra en los procesos participativos, incluyendo a los niños en la toma decisión sobre su entorno vital, en Lavapiés (Madrid). En el tercero, la operatividad de las herramientas se muestra también en los resultados de la investigación sobre participación ciudadana en el distrito de Barranco (Lima), influyendo en la enseñanza en varias Maestrías en los departamentos de Ciencias Sociales y Arquitectura en la Pontificia Universidad Católica del Perú (PUCP, Lima).

El conjunto creciente de técnicas y herramientas que se analizan aquí tiene su aplicación práctica desde el 2008 hasta 2010 en el marco del Máster en Educación Intercultural que lleva a cabo la Universidad Nacional de Educación a Distancia (UNED, España) con la Universidad Veracruzana (UV, México) y, entre el 2015 hasta 2017, dentro del marco del Máster Universitario en Formación del Profesorado de Educación Secundaria de Ecuador, gracias al Convenio Específico de Cooperación Interinstitucional entre el Ministerio de Educación en la formación del profesorado de Educación Secundaría. Este módulo del Máster se centra en vincular la dimensión sociopolítica de la ciudadanía/ democracia con la "educación intercultural" en el contexto sociedad-familia-escuela. En este curso se trabaja la motivación de impli- 
cación de los niños como "expertos" en la toma de decisión de cambios cualitativos de su hábitat, introduciendo las teorías básicas para reunir herramientas operativas de participación ciudadana aplicables en el aula. En estas experiencias de nivel no escolar se observa la operatividad del conjunto de técnicas para su uso y aplicación interdisciplinar y, especialmente, en el campo de la Educación, para profundizar en cuestiones como procesos participativos, entornos sociales y la percepción de calidad de vida ${ }^{1}$.

\section{¿Viable O ÚTIL? LO “TÉCNICAMENTE POSIBLE"}

A PRUEBA DE LA VIDA COTIDIANA

Durante las últimas décadas, especialmente en el ámbito de la postguerra europea, la misión de la Arquitectura como ciencia de ingeniería es hacer frente a las transformaciones sociopolíticas a través de una posición de lo "técnicamente posible"; de esta manera, deja de lado a la arquitectura de la cotidianeidad con sus manifestaciones de estructuras humanas, símbolos y funciones (Omahna, 2013, p. 40). Esto también implica un desafío frente al grado de cientificidad del área y, ante todo, sobre la formación profesional en él. Desde los años 80 del siglo pasado, se aprecia dentro del ámbito europeo, una desviación institucional en las facultades de Arquitectura, aumentando el profesorado y cátedras ocupados por científicos sociales.

Este momento histórico, ubicado en la postguerra europea de los años cincuenta y sesenta, exige respuestas a temas como la reconstrucción de áreas destruidas, en pugna con la explosión de la población y el crecimiento urbano generalizado. Un eslabón del interés de los estudios históricos entre Arquitectura y Antropología en la literatura académica alemana es el campo de Hausforschung que indaga en la evolución de los materiales, planes y terrenos o la investigación sobre la casa tradicional, un campo crucial de etnología europea ${ }^{2}$. Este último se centra en estudiar la relación de las personas con su hábitat vital o, si se prefiere, en el análisis de la cultura respecto a sus prácticas espaciales. Omahna (2013) enumera como temas sinérgicos entre las dos ciencias: la investigación sobre edificios y paisajes históricos que muestran el proceso sociocultural de cambio; las tipologías constructivas y la organización del espacio; la cultura de la edificación en sí misma; y finalmente, el uso del espacio por los agentes sociales o las instituciones que por "las lógicas de sus prácticas específicas sobre el espacio provocan cambios de éste" (Omahna, 2013, p. 41). Saliendo de esta manera de lo plenamente "construido", las sinergias de investigación compartidas se centran en el interés por cuestiones acerca de una "identidad espacial", un intento de "dibujar lo urbano", las formas de habitar la urbe y los nuevos retos relacionados con los estilos de vida, la movilidad y las particularidades intrínsecas de cada ciudad. En este punto es importante mencionar que la lógica de investigación es distinta según se trata de sociedades igualitarias o sociedades segmentadas.

En su trabajo sobre el diálogo entre Antropología y Arquitectura, Omahna (2013) remarca la importancia de averiguar dónde se verifican los resultados recibidos y de indagar sobre la repercusión de estas investigaciones dentro del funcionamiento de un sistema social concreto. El autor, for- 
mado en ambas disciplinas, se pregunta qué es lo que la Antropología puede aportar para mejorar la comprensión de la relación entre el espacio y las personas, reconociendo que el interés de los arquitectos por los enfoques antropológicos es mayor que en la dirección contraria. El conocimiento disciplinar en la Arquitectura tiene como objetivo la producción o aportación de soluciones respecto a problemas espaciales, pero Omahna (2013) argumenta que la Antropología se centra en la comprensión de las causas en problemáticas concretas. Tomando en cuenta las dinámicas de ambas disciplinas, se trata de buscar diferentes modos de una forma de expresión común para trabajar con éxito la percepción subjetiva de la dialéctica entre las capacidades habituales de las personas y el espacio construido. A raíz de esto, como argumenta el autor, se ofrece la posibilidad de descubrir en realidad nuevos campos de conocimientos provechosos para ambas disciplinas. De ahí que Omahna (2013) formulase su pregunta primordial: “¿Cómo conseguir que el hombre posicione su identidad en un espacio social en la intersección entre el deseo personal y la atribución social?” (p. 47).

El subcampo con perspectiva antropológica de la Arquitectura, donde se posiciona este autor, trata de conseguir una suspensión temporal entre planificación y Lebenswelt ${ }^{3}$. En consecuencia, se trata de analizar las prácticas culturales que reflejan los valores y creencias de los miembros de una comunidad que a menudo abarcan generaciones, sirviendo "a las personas para hacer frente a las exigencias de su entorno vital, entendiendo éste en proceso permanente $y$, por lo tanto, como un campo de estudio interdisciplinar" (Omahna, 2013, p. 47). En esta línea, Omahna ve la función de este nuevo espacio dentro de la Arquitectura y se esfuerza en definir la producción cultural del espacio como una práctica social que traduce las necesidades del mundo vivo y las estrategias de procesamiento cultural en gramáticas de acciones vividas y orientadas espacialmente. El autor subraya la necesidad de indagar "cómo las personas pueden hacer frente a las demandas de su entorno" como un proceso permanente de investigación, más allá de los límites de las competencias de estas disciplinas y crea, de esta manera, un espacio real para un pensamiento interdisciplinar fructífero, no sólo entre los dos campos aquí mencionados, sino abierto a todos los ámbitos que centran su mirada en la convivencia de las personas (Omahna, 2013, p. 48).

Otro texto, sobre la sistematización de herramientas metodológicas esclarecedor para ambas disciplinas, se centra en los buenos resultados recibidos por equipos compuestos de arquitectos y antropólogos para el desarrollo del trabajo de campo dentro del proceso de investigación realizado sobre el proyecto Casa Amarilla (Alemania) ${ }^{4}$. La aplicación del método cualitativo que ofrece la Antropología -etnografía cualitativa y contextualizada- presenta, para Laister y Hieslmair (2013), un beneficio para la Arquitectura sobre todo por su competencia analítica de la vida cotidiana:

La etnología es capaz de poner un espejo en el cual puedo observar mi actitud como arquitecto [...] Entra en uno de los más importantes temas de cada profesión la repercusión de tu propia acción en la vida cotidiana de los demás. Y esto, en el caso de arquitectura, no me lo ha podido explicar hasta este momento nadie. (p. 168)

Pero es el Taller de Investigación de la Facultad de Arquitectura de la $\mathrm{PUCP}^{5}$ el 
lugar donde durante varios años pudimos observar la aplicación de técnicas cualitativas, aportadas por la Antropología Urbana, como un campo de fructífero contacto entre las dos disciplinas. Introduciendo este taller en el proceso de la elaboración de proyectos, en muchas ocasiones, observamos la reorganización de una hipótesis inicial por parte del estudiantado, tras haber visitado la localidad elegida para la intervención. Una vez entrevistadas las personas seleccionadas, se puede decir que hubo un desajuste del afán estético a favor de la funcionalidad y del gusto local. Al mismo tiempo, la fase de observación participante del alumnado de Arquitectura proporciona una valiosa información de las dinámicas y necesidades reales locales. Estas informaciones adicionales, junto a una implicación personal en entrevistas in situ, producen precisamente esta clase de responsabilidad que mencionan anteriormente Laister y Hieslmair (2013).

En mi opinión, observar el conjunto del verde social, los parques o los jardines urbanos y los espacios públicos de la urbe, sin dejar fuera la calle como componente de la unidad de estudio, forma un laboratorio fructífero y fascinante como "zona de contacto" de las dos disciplinas, centrándonos aquí en la dimensión social. En cada instante hay más de lo que la mirada puede captar a simple vista y lo que se puede registrar sensorialmente, es decir, un escenario o un panorama nuevo para ser explorado. A lo largo de mis últimos veinte años de investigaciones centradas en diferentes proyectos sobre el verde urbano, participación ciudadana, Agenda 21 local, etc., desarrolladas en varias ciudades (Viena, Madrid, Lima y Manizales), puedo elaborar un útil tool-kit para trabajar este terreno enmarcado dentro de la Antropología Urbana.
Este tool-kit se alimenta, fuera del método cualitativo, de herramientas y técnicas prestadas por disciplinas afines como la Geografía Humana, el Urbanismo y la Geografía Ambiental. Este "laboratorio" con su peculiar conjunto, día a día, da lugar a movimientos sociales de agrupaciones/individuos, y por lo tanto es terreno "de pruebas determinantes sobre lo correcto y lo incorrecto, lo conveniente y lo tolerable en nuestra sociedad" (Joseph, 1999, p. 72). A lo largo de estos años, el reto de intervención en estos proyectos, respecto al espacio verde y público, ha sido afinar el conjunto de herramientas operativas para hacer visibles las nuevas "misiones" del verde urbano y el aumento de su importancia como espacio de terapia, de "colchón de choque", para dirigir el progresivo caudal de ansiedad y depresión en nuestra sociedad. Obviamente, esto está relacionado con problemas difíciles de resolver: personas con paros de larga duración, inmigrantes en la búsqueda de un lugar de encuentro o el aumento del porcentaje de personas mayores que acuden a estos espacios para pasar el tiempo.

Estos grupos son poco homogéneos entre sí, pero les unen algunas características como la disposición de mucho tiempo libre que sobrepasa la noción de "tiempo de ocio" y se combina con el hecho de tener escasos recursos económicos. Según las observaciones realizadas, se ha entendido como inevitable analizar el tratamiento del concepto de "tiempo libre" en las Ciencias Sociales y trabajar sobre el momento en que este empieza a ser estigmatizado por la sociedad. De este modo, es necesario buscar respuestas positivas cuando el tiempo libre ya no se contrapone al tiempo que ocupa el trabajo remunerado, como sentido único de vida, es decir, cuando pasa de ser una situación deseada a un problema diario ${ }^{6}$. 
Aparte de las herramientas y técnicas discutidas dentro de los diferentes casos de estudios concretos, debemos añadir que, para este laboratorio, el concepto del "ojo social" de Jacobs (1973) es un enfoque imprescindible para estudiar el terreno público de la urbe. De la misma manera, resulta clave no perder de vista la lógica intrínseca ${ }^{7}$, los ritmos y la tendencia a la disociación y división como patrones dominantes en las ciudades. Las herramientas y técnicas descritas en este texto han sido aplicadas en diferentes contextos geográficos con distintas combinaciones. En otras palabras, el conocimiento político, histórico y socioeconómico de la "personalidad" de cada ciudad es el primer paso o la primera cuestión al definir la composición de las herramientas para estudiarla. Finalmente, hay que mencionar el trabajo de Lynch sobre las ciudades de Boston, New Jersey y Los Ángeles (1966), en el cual se observa que todos los ciudadanos tienen vínculos estrechos tanto con una u otra parte de la ciudad como con los diferentes espacios verdes existentes en ella. Su imagen está llena de recuerdos y significados, se puede decir que casi todos los sentidos están en acción y la imagen mental, como veremos más adelante, es una combinación de todos ellos. Las técnicas que se implican en las investigaciones con- cretas resaltadas en este texto sirven como herramientas a la hora de transformar estas imágenes mentales en escritos, conseguir su comprensión o, como dice Lynch (1966), permitir su "legibilidad".

En el medio urbano, hoy en día, resulta difícil perderse por completo. Nos apoyamos en la presencia de los demás y en herramientas específicas para la orientación como suelen ser, por ejemplo, los mapas, la numeración de las calles, las señales de tráfico o los letreros de los autobuses. La necesidad de reconocer y estructurar nuestro entorno es de vital importancia para nuestro desarrollo individual, así las imágenes que construye nuestra mente tienen una importancia práctica y emotiva para nosotros como individuos. Siguiendo a Lynch (1970):

Las imágenes ambientales son el resultado de un proceso bilateral entre el observador y su medio ambiente. El medio ambiente sugiere distinciones y relaciones y el observador -con gran adaptabilidad y a la luz de sus propios objetivosescoge, organiza y dota de significado lo que ve $[\ldots]$ la imagen desarrollada $[\ldots]$ limita y acentúa lo que se ve, en tanto que en sí misma es contrastada con la percepción filtrada, mediante un constante proceso de interacción. De este modo, la imagen de una realidad determinada puede variar en forma considerable entre diversos observadores [...] (p. 15)

\section{EL DIBUJO COMO HERRAMIENTA ETNOGRÁFICA}

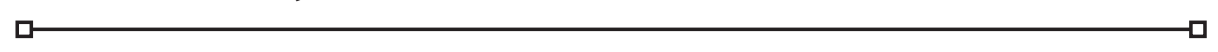

El dibujo es una técnica que se ha rescatado de nuevo en Antropología como herramienta de campo. En este terreno, generalmente, la calidad y el hábito de elaboración son más frecuentes en la Arquitectura. Existen diversas opiniones sobre el dibujo como herramienta etnográfica, por eso, a continuación, se detallan autores como
Kuschnir (2016) y Klengel (2017) tras analizar los datos aportados por sus informantes Schäfer y Tondeur y sus consideraciones.

El dibujo como herramienta casi no se trata en los manuales etnográficos contemporáneos salvo, como anteriormente se ha mencionado, en los mapas cognitivos y, en 
este caso, elaborados por las personas entrevistadas y no por el investigador. Por esta razón, la aportación de Kuschnir (2016) sobre la valoración y el potencial del dibujo etnográfico en un viaje por las monografías de los autores más relevantes desde un enfoque de la antropología tradicional es muy enriquecedora ${ }^{8}$. Aquí, en contraposición, nos referimos a la elaboración de estos documentos gráficos por parte del investigador y a las fases del proceso de la investigación en las que pueden ofrecer su aportación operativa.

Klengel (2017) argumenta que el dibujo "como herramienta propia en el proceso etnográfico, se presta a la reflexión y la producción de conocimiento, además de ser un catalizador social dentro del trabajo de campo" (p. 12). En combinación con la observación participante y la entrevista, se presta a captar la atmósfera y la práctica espacial del lugar heterotropo en el que se realiza. Esta práctica, más aún que la fotografía, exige la selección por parte del investigador ya que sólo unos cuantos aspectos pueden recogerse en la hoja del dibujante, mientras que otros se quedan ausentes. Este proceso, como dice Klengel (2017), no deja de ser subjetivo, pero esta selección "forzada" ofrece a su vez la ventaja de abstraer esta información visual que crea el efecto de densificación. De la misma manera, y como si se tratase de un texto, el dibujo requiere unos procesos de traducción previos que hacen posible que lo "ocurrido" se incorpore como un eslabón en una cadena de argumentación (Klengel, 2017, p. 13). El dibujo en sí mismo alcanza voz a través de la contextualización con el resto del material empírico. En esta línea se ve la argumentación del informante Schäfer, investigador urbano y artista:

Dentro del pictorial turn, en el campo de la Antropología Cultural actual, la práctica del dibujo ha encontrado su lugar entre la fotografía y la película etnográfica; de hecho, en la actualidad, es de nuevo parte constitutiva y metodológica en la enseñanza de la Grafic Anthropology Field School que lleva a cabo Kim Tondeur, miembro del Instituto Antropológico en Graz (Austria), en Gozo (Malta). La virtud de la herramienta está entre otros aspectos en la inversión de tiempo que tarda en elaborarse. Exige una decisión concienciada de la elección del motivo. Se trata de un proceso mental activo donde la información visual recibida es procesada por el investigador y plasmada bajo su comprensión de la situación. Kuschnir (2016), en sus once argumentos en favor del dibujo dentro del trabajo de campo, opina que es una herramienta que ayuda al investigador a realizar su estancia en el campo: “quien dibuja está ocupado, de esta manera tiene un sitio, forma parte dentro de la situación de campo". Esta ocupación tiene una doble vertiente, por un lado, ayuda al investigador a justificar su presencia y, por otro, es percibido por los entrevistados como una persona útil dentro del proceso. El dibujo se ha prestado en el estudio realizado con niños de Lavapiés como una herramienta excelente para trabajar sobre la remodelación de una plaza de esta barriada y para recoger su opinión experta como agentes activos de participación ciudadana (Müllauer-Seichter, 2010; 2013b).

\section{TÉCNICAS PRESTADAS: HOJAS DE FRECUENCIA Y RECOGIDA DE DATOS IN SITU}

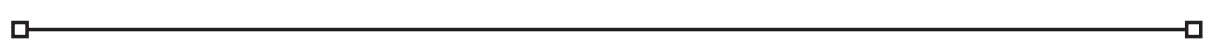

Las hojas de frecuencia representan una herramienta de trabajo para observar las franjas de tiempo empleadas por los distintos usuarios en días laborales y fines de 
semana de manera puntual. El objetivo es descubrir, en puntos concretos del territorio, los niveles de uso existentes, la naturaleza de la demanda de los usuarios y el valor de las oportunidades recreativas en las unidades de estudio.

Se aprecia la importancia de estas técnicas de estudio en los siguientes terrenos a observar: la Casa de Campo y el distrito de Lavapiés en Madrid y varios parques en Lima (Perú). La recogida de datos en el caso del estudio sobre la Casa de Campo permite elaborar un cuadro con la variedad de perfiles de usuarios, trabajando en las pautas de las visitas, tanto en el tiempo como en el espacio. La elaboración de estas hojas está en estrecha relación con la observación participante y, por tanto, con la recogida de apun- tes personales de observación in situ en el diario de campo, con el fin de elaborar una hipótesis inicial sobre el objetivo de investigación que es, en esta ocasión, el valor que cobra este espacio en la identidad madrileña. Dependiendo del terreno a observar, se define los puntos claves dentro de la unidad de estudio. En este caso la unidad de estudio es un parque urbano, pero la aplicación de la herramienta se ha mostrado sumamente útil en estudios realizados en el distrito céntrico de Lavapiés (Madrid) sobre los sitios preferidos de los niños en su entorno vital para disfrutar el tiempo libre (figura 1). De la misma manera, las hojas de frecuencias ofrecieron interesantes resultados sobre los usos de varios parques en Lima (Perú) dentro de un taller sobre Técnicas de investigación sobre el espacio público (2013, PUCP).

\section{Figura 1}

Dibujo de niños en Lavapiés.

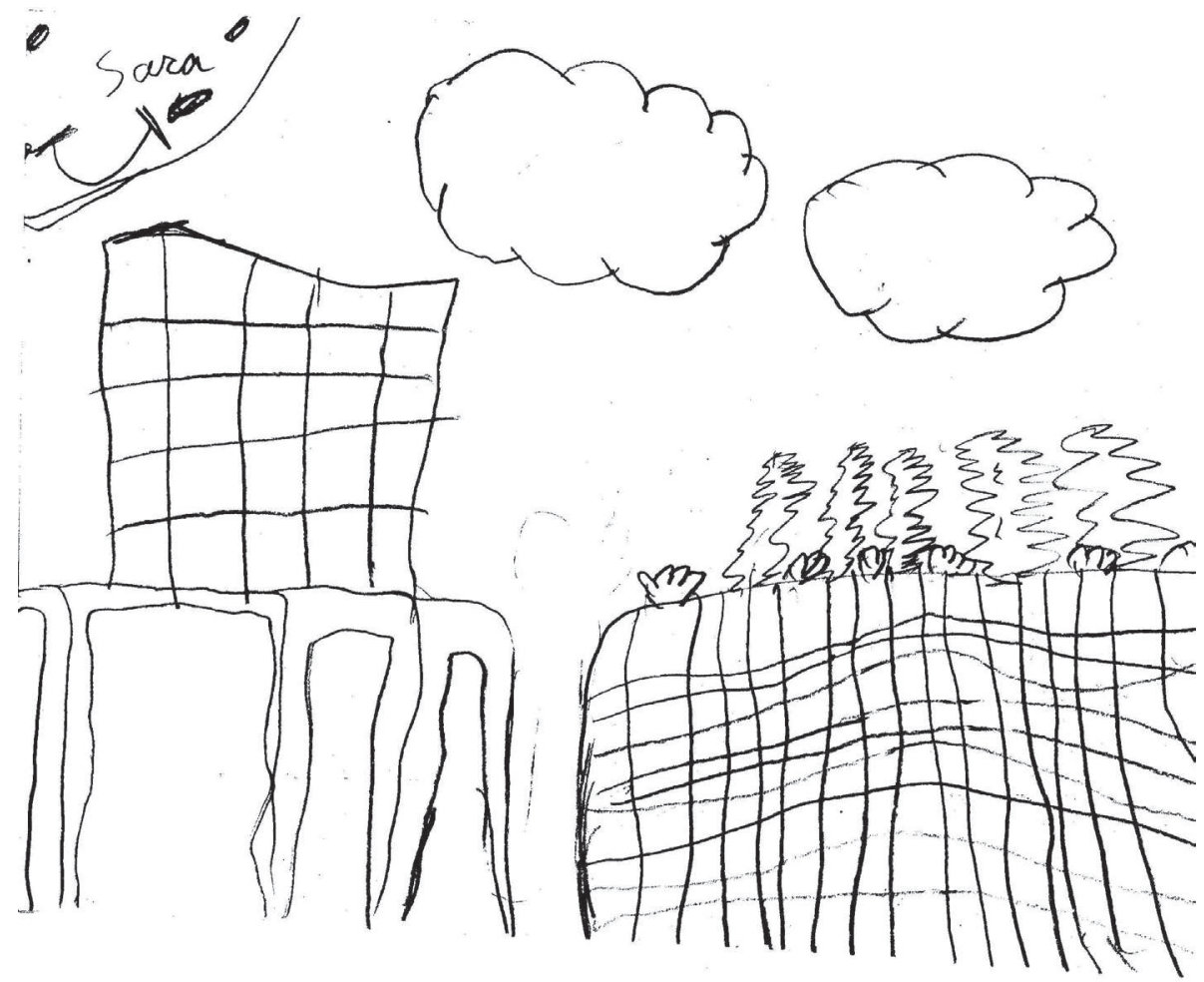

Fuente: W. Müllauer-Seichter (2007). 


\section{EXCURSIÓN URBANA, MAPAS MENTALES Y FOTOGRAFÍAS}

Para trabajar el espacio público, la función y las necesidades que debería cumplir para los ciudadanos en sus diferentes formatos, resultan de especial interés la combinación de dos técnicas prestadas: el "paseo urbano" procedente de la Geografía Humana y los mapas cognitivos del Urbanismo. Aquí se evalúa las dificultades que cada una de ellas presenta a la hora de aplicarse a unidades de investigación seleccionadas para mencionar, después, otras dificultades que surgen en el desarrollo del trabajo de campo tanto en el espacio verde, en el caso de plazas urbanas y, finalmente, el uso de las técnicas adaptadas al trabajo con niños y jóvenes en el estudio de Lavapiés.

\section{La Excursión urbana: los paseos a la deriva}

Tal como describen los autores de las Prácticas de Geografía de la percepción y la actividad cotidiana (1992), el ejercicio se aplica en dos modalidades y consiste esencialmente en un paseo sin itinerario predeterminado durante el cual, el sujeto va indicando sobre un diario una serie de cuestiones que le parecen pertinentes. La modalidad de excursión es implementada en los trabajos de Lynch (1966) y Bailly (1979), siguiendo la hipótesis que la comprensión de lo que es la ciudad supone conocer las connotaciones que provoca en el individuo, todo lo que en él refleja, el sentido que le da y la modificación, a veces inconscientemente, de sus actitudes y su forma de comportarse.

Con la aplicación de esta técnica se admite que la realidad como tal no existe, excepto a través de nuestros esbozos mentales percibidos, reconociendo, a la vez, que nuestras representaciones cognitivas del espacio ya han traspasado una serie de filtros como: los personales (sexo y edad); el medio socio-profesional; y el grupo de pertenencia social (cultura e ideología política). El ejercicio se desarrolla en tres etapas. La primera modalidad es un paseo a la deriva en el que los sujetos se concentran en descubrir las estructuras físicas que organizan el espacio urbano. Una vez terminada esta tarea se discute las impresiones adquiridas. El sentido de este ejercicio se encuentra en la codificación del orden espacial dentro de una realidad urbana concreta. Como mencionan Bosque-Sendra, Castro-Aguirre, Díaz-Muñoz y Escobar-Martínez (1992), la importancia está en que los informantes conozcan el sentido del ejercicio. Para este fin, se les entrega una hoja que les sirve de diario y que contiene cuatro categorías: punto de cambio; elemento significativo; connotación; y, motivo de cambio como expone este grupo de autores $(1992$, p. 88). Esta etapa prevé el uso de otro documento preparado para los participantes en el que se marca los elementos significantes en el proceso del $p a$ seo a la deriva y también las connotaciones percibidas respecto a estos elementos observados.

Estos investigadores (1992, p. 90) describen una segunda modalidad, la valoración de los barrios que puede realizarse por pequeños grupos. Los autores ven necesario para esta modalidad, un plano de la zona en cuestión sobre el que se marca el recorrido "señalando también los límites y núcleos de 
la zona visitada" (1992, p. 91). Se trata de un recorrido diseñado por los informantes de manera individual, exponiendo los motivos que han influido en la orientación y recorrido concreto del camino. Es la base sobre la cual se expresan las impresiones adquiridas durante del ejercicio con el fin de confrontarlas con el conocimiento previo del espacio en cuestión. El objetivo es comprender la heterogeneidad de las distintas zonas, recorriendo sus límites e identificando sus elementos estructurantes. La última parte de la excursión es de verificación. Aquí se contrastan las impresiones individuales con la documentación existente o con los conocimientos de expertos (guías y mapas urbanísticos de la ciudad) para conseguir una triangulación de fuentes. Hay que elegir entre la disyuntiva de dar prioridad al estudio del área total de la ciudad o al de una zona concreta, recorrida simultáneamente por varios sujetos.

Para el desarrollo del trabajo de campo que se realiza en la Casa de Campo, el diseño de la aplicación de esta técnica varía de acuerdo con otras investigaciones realizadas en un contexto más urbano, con el fin de identificar y resolver el problema que interesa en cada cuestión estudiada. Con la finalidad de elaborar una clasificación de usos del parque más grande de la capital españo$\mathrm{la}^{9}$, se decide escoger de la muestra de informantes a cinco personas, todos varones de avanzada edad y miembros de un colectivo "clandestino" que cuida jardines en diferentes puntos. Esta decisión se justifica por el conocimiento sobre la totalidad del terreno y por la posibilidad de trabajar el eje temporal a través de la profundidad de memoria que ofrecen los sujetos seleccionados. En este caso, el ejercicio sufre una modificación en la práctica ya que no se realiza con un grupo de personas sino individualmente. Todos los implicados que se prestan a hacer "el paseo" han participado previamente como interlocutores en entrevistas semiabiertas y forman parte en la elaboración de los mapas cognitivos. La ventaja de que participen en varias técnicas es que están al corriente de lo que se espera de ellos. En la aplicación de este estudio concreto sobre la Casa de Campo en Madrid, queda fuera la etapa del paseo a la deriva porque todos los participantes tienen un amplio conocimiento del terreno. En general, el problema de esta muestra concreta es la alta tasa de personas mayores, así como la tasa de varones ya que las mujeres casi no figuran en ciertos colectivos que encontramos en este parque como "jardineros", jugadores de chito, toreros, pescadores, etc. Para el estudio tampoco tiene mucho sentido que ellos vayan solos, sino que se les acompaña durante todo el camino con una grabadora de voz. El inicio de cada paseo es elegido por las distintas personas de forma que indican alguna entrada al parque, una boca del metro, etc., desde donde se comienza el recorrido.

El ejercicio tiene una duración de entre tres horas y media a cuatro y comienza con un esbozo del recorrido elegido, apuntando una estimación del tiempo necesario para moverse entre los distintos puntos de referencia en el territorio. Durante el camino, las personas documentan los lugares significativos. Al final del paseo, se repasa de nuevo el dibujo realizado al principio del ejercicio para comprobar si ha habido desvíos del recorrido propuesto. Aplicar la técnica fuera de su escenario urbano puede ofrecer respuestas interesantes respecto a la orientación en un entorno sin edificación y aparentemente sin ayuda de señalización. Como resultado, se muestra un sistema de orientación origi- 
nal construido en la memoria personal y un sistema de designación particular de puntos de referencias arraigados en la procedencia rural de este grupo de informantes que sabían encontrar lugares, por ejemplo, el sitio para buscar esparrago salvaje, setas, frutos salvajes, etc.

En otras ocasiones, esta técnica se aplica en su entorno original, urbano, como en los estudios en el centro de la ciudad de Madrid y en el distrito de Barranco (Lima), aportando en sus respectivas adaptaciones resultados interesantes. La técnica resulta aún más esclarecedora cuando se combina con la práctica de los esbozos cognitivos y, con entrevistas semiestructuradas previas.

\section{Mapas cognitivos}

Para comenzar este apartado, una definición muy concreta del término percepción es necesaria. Probablemente, este podría reducirse a la comprensión básica por medio de los cinco sentidos (vista, oído, tacto, olfato y gusto). La aplicación de este término para describir el desarrollo del medioambiente comprende lógicamente mucho más. Por tanto, el espacio cognitivo nos ofrece lo que se denomina "representación cognitiva", cuya materialización sobre un esbozo es la llamada "configuración cognitiva". Estas realidades son construidas por cada sujeto a su manera, según su trasfondo personal y sus experiencias vitales. Para muchos investigadores, este proceso debería llamarse cognición, indicando mejor ese desarrollo de una conciencia del ambiente. Por tanto, no es la consecuencia de los estímulos si no la forma cómo el individuo aprende sobre el entorno en el que vive. Entonces, se puede decir que no es de gran importancia descri- bir qué aprende el individuo, si no cómo interpreta lo que aprende. La constelación de las estructuras que desarrolla cada individuo pone de manifiesto qué es lo que ve en el mundo real; aunque se puede predecir, en cierto grado, que personas en similares situaciones tienen la tendencia a adoptar construcciones parecidas de su entorno. En esta línea, Müllauer-Seichter (2003) describe que el "proceso de mental mapping se refiere a aquel por el cual el individuo adquiere, codifica, memoriza, renombra y manipula la información sobre la naturaleza de su entorno" (p. 55).

En su trabajo, Lynch relata que los esbozos mentales difieren en varias ocasiones de las imágenes que se describen de forma verbal en las entrevistas (1966, p. 167); un problema que se aprecia en el estudio sobre el parque madrileño. En el caso de la Casa de Campo, el aspecto que Lynch observa se aprecia en relación con las numerosas cesiones de terreno, sobre todo después de 1931. En los dibujos de los mapas mentales de los sujetos entrevistados no se plasman estos conocimientos históricos sobre este espacio.

En cambio, en la narrativa recogida de los relatos de los sujetos entrevistados, en una fase posterior al dibujo y en la grabación explicativa de este, sí se manifiesta en casi todos los testimonios esta fecha clave de la entrega del parque al pueblo de $\mathrm{Ma}-$ drid. En esta experiencia vital se observa la conciencia social y derecho legítimo de uso por la condición de ser ciudadano de Madrid. Esto se muestra en los momentos en que los entrevistados hacen hincapié en las injusticias que se producen en algunas prestaciones temporales o recortes de terreno (como lo denominan los entrevistados) a favor de empresas privadas o instituciones. 
La combinación de estas técnicas muestra también resultados interesantes en Lima sobre el impacto que tiene la implementación del Metropolitano ${ }^{10}$ en los itinerarios habituales de los vecinos de este distrito ${ }^{11}$. Desde el material empírico de la investigación en Barranco, se refleja bien la reducción del espacio público, mientras que la construcción privada se muestra como barrera en los itinerarios habituales de las personas entrevistadas. Precisamente estos hechos aparecen cuando se contrasta la información en el mapa cognitivo con el esbozo de la propuesta del paseo.

Finalmente, respecto a los esbozos mentales en el estudio del espacio vital con los niños de Lavapiés parece que, entre 6 y 9 años, poseen una visión concreta del espa- cio y aprenden a orientarse usando puntos de referencia que tienen que ver con el lugar donde crecen: en las zonas rurales a través de árboles, montañas, etc.; y en entorno urbano, por edificios, glorietas, plazas, etc. La noción de tiempo en esta edad es vaga, los términos del ciclo vital (ayer, hoy, mañana, una semana, un mes) se manejan con dificultad. Los niños de esta edad se guían más bien por la espontaneidad y el impulso. El primer trabajo que realizan los niños consiste en representar la plaza "real". Es interesante lo que identificaron como "lugares de peligro": zonas donde se reúne gente sin techo para beber o para dormir. Estos lugares parecían "eclipsados" de los dibujos, de manera que queda reflejado sólo el espacio "positivo", apto para el juego (figura 2 y 3 ).

\section{Figura 2}

Esbozo de niños en Lavapiés.

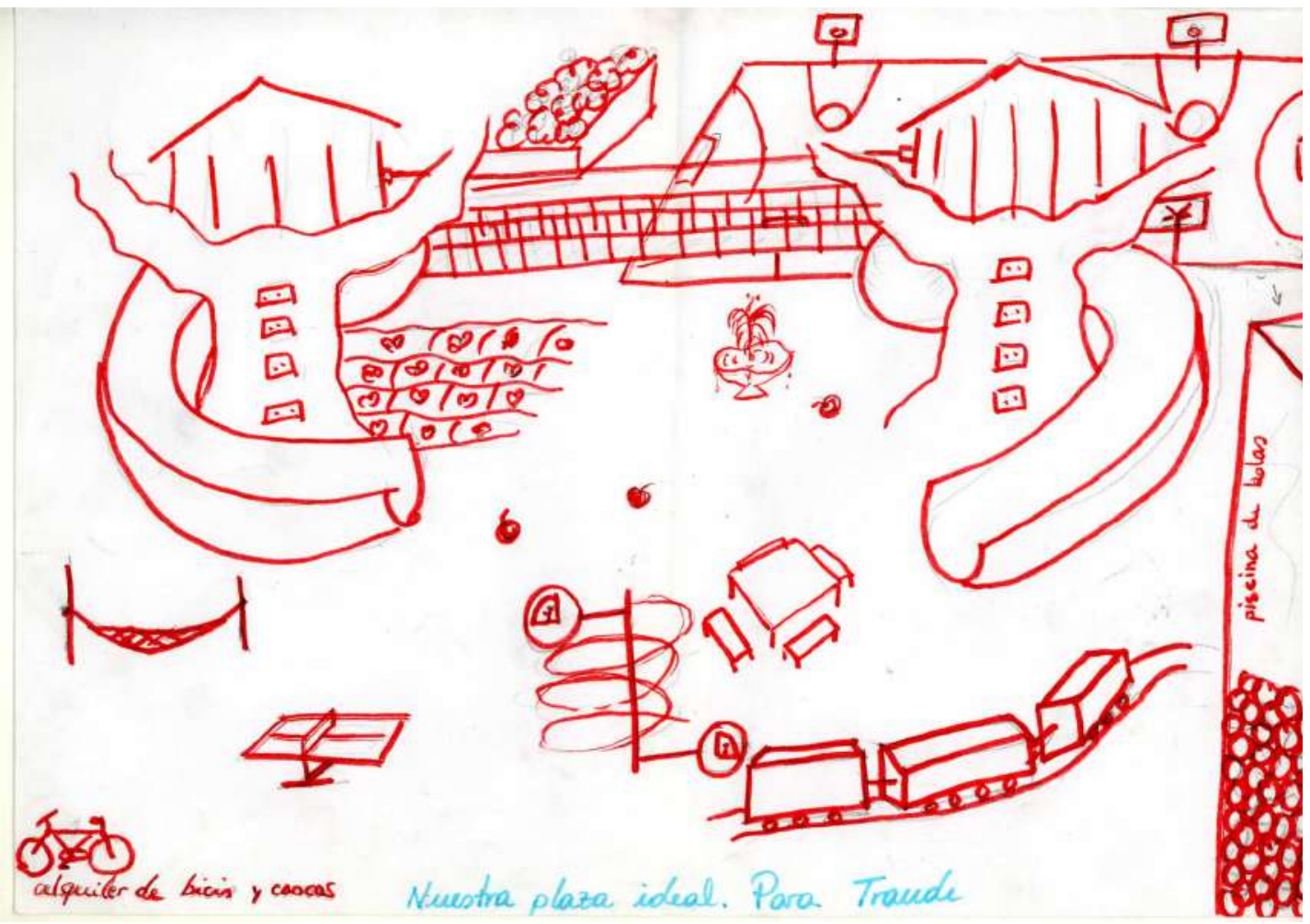

Fuente: W. Müllauer-Seichter (2007). 


\section{Figura 3}

Plaza Agustín Lara, Lavapiés.

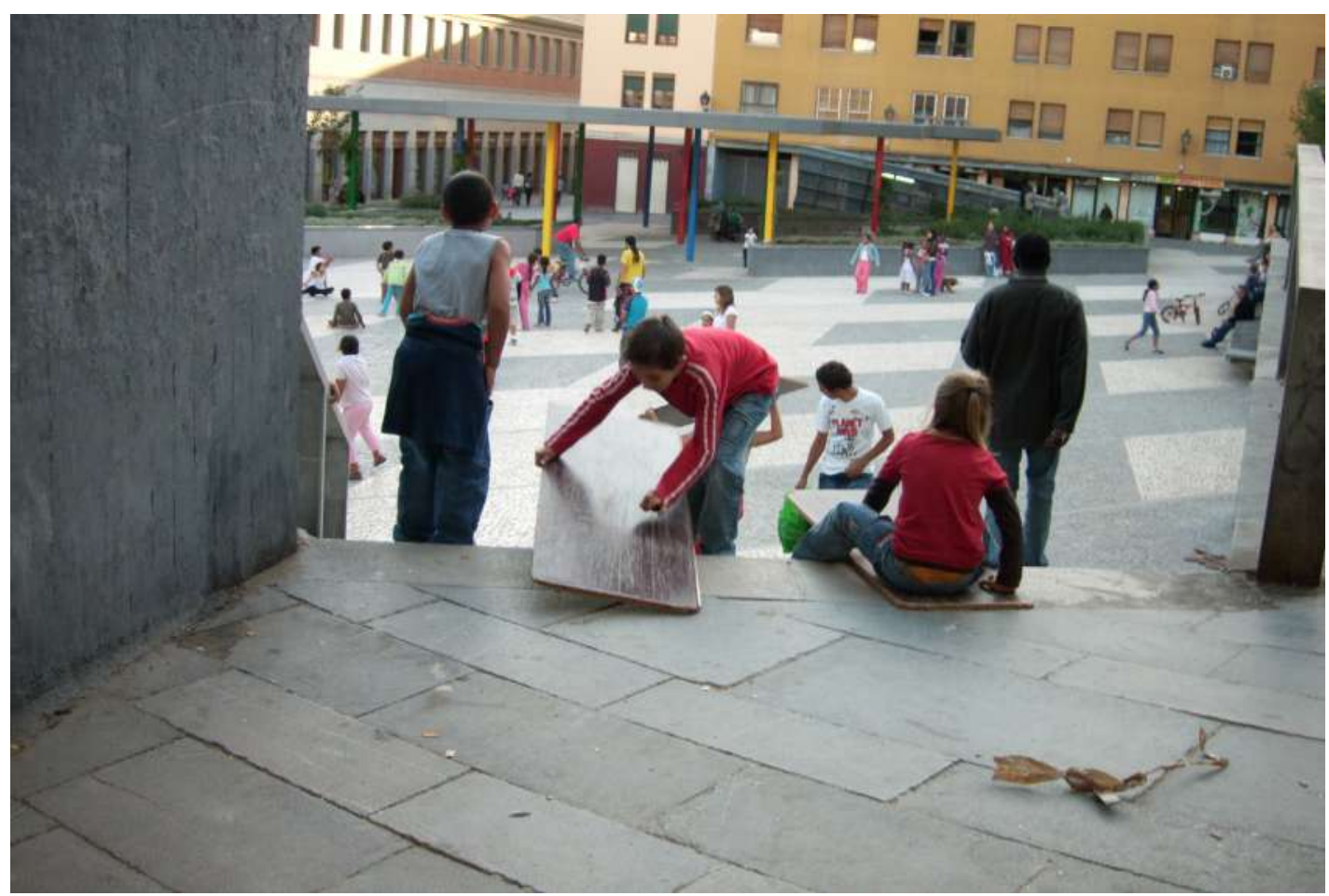

Fuente: W. Müllauer-Seichter (2007).

\section{Fotografias}

El método de Lynch es fundamental para trabajar con las imágenes designativas, aunque este hecho causa el dilema de que no ofrece información sobre lo que siente o percibe el individuo de su entorno. Es decir, su debilidad es que se centra en la legibilidad e imaginación y no en la percepción (Walmsley, 1988, p. 45). Para evaluar la cuestión de lo estético y la percepción consciente de las subáreas del lugar hace falta recurrir a técnicas visuales. Para llenar estas lagunas de información, Hudson y Pocock (1978) proponen un estudio apreciativo de la imagen. Estos autores distinguen dos fuentes de imágenes: la imagen evaluativa, en la cual los individuos dan su opinión sobre el ambiente que ven; y la imagen afectiva, en la que deben especificar las preferencias respecto a diferentes partes que aparecen en ella. Desde la experiencia en estudios prácticos con este enfoque, hay que mencionar que en muchas ocasiones se utilizan los términos de imagen apreciativa/imagen afectiva de la misma manera (Walmsley, 1988, p. 45).

Respecto al uso de fotografías, uno de los problemas con este tipo de investigación es que la dimensión a lo largo de la cual se debe evaluar un entorno tiene que ser especificada por el investigador (por ejemplo, atractivo-poco atractivo, silencioso-ruidoso, hermoso-feo), y no hay forma de saber si los encuestados consideran que estas dimensiones son importantes (Walmsley, 1988, p. 44).

Gould (1966) menciona ciertas críticas 
de investigadores respecto a la utilidad de resolver preguntas sobre problemas espaciales, a través del uso y la interpretación de mapas cognitivos; aspectos que le llevan a buscar nuevas formas de estudiar las imágenes (Walmsley, 1988, p. 48). Entre una serie de técnicas proyectivas, Walmsley $(1988$, p. 47) resalta las propuestas de Saarinen (1973). Por razones logísticas, se ofrece enfrentar al informante con fotografías tomadas en el terreno de la unidad de estudio. En los trabajos realizados en el parque de Madrid se aplicaron dos técnicas: Word Association Test y Thematic Apperception Test. La primera técnica es un procedimiento desarrollado por el psicoanalista Jung para investigar cómo se almacenan los significados de las palabras en la memoria. Se trata de una prueba de asociación donde el investigador presenta una serie de palabras a los encuestados individuales. Para cada palabra, se les indica a los participantes que respondan con la primera palabra (es decir, asociada) que le viene a la mente. Ambas técnicas son préstamos de la Psicología donde se utiliza este primer procedimiento para investigar cómo se almacena la información semántica en la memoria. Los estudios han demostrado que las asociaciones de palabras casi siempre se basan en el significado de una palabra, en oposición a sus propiedades físicas. A lo largo de los años, los psicólogos han recopilado una serie de normas que describen las frecuencias relativas con las que se dan diversas respuestas a diferentes palabras. En el caso del Thematic Apperception Test se trata de una prueba proyectiva desarrollada durante la década de 1930. Los defensores de la técnica afirman que las respuestas de los sujetos, en las narraciones que componen sobre imágenes ambiguas de personas, revelan sus motivos subyacentes, preocupaciones y la forma en que ven el mundo social. Históricamente, esta prueba ha estado entre las técnicas más investigadas, enseñadas y utilizadas.

Estas técnicas son aplicadas en varias de las investigaciones descritas. En el estudio sobre la Casa de Campo se utiliza un juego de fotos del parque para preguntar en qué lugares creen que se habían tomado las fotos (Müllauer-Seichter, 2004). Además, su empleo en Lavapiés provee resultados interesantes en un estudio sobre la reforma de plazas urbanas en Madrid, realizado en este caso con niños (Müllauer-Seichter, 2010; 2013b). Finalmente, se incluye en este apartado la "tomada de fotos" como estrategia útil de investigación. En el estudio de Lavapiés, la investigación consiste en dotar a los niños de cámaras digitales para que recorran su entorno habitual tomando fotos en los espacios que frecuentan para el juego, sacando imágenes que representan ejemplos de los elementos que deben o no formar parte de "su plaza ideal". Las fotos, ordenadas según la división plaza/parque, son expuestas en una pared en el centro social de la institución y sirven como "fondo" o escenario para la segunda "vuelta" de grupo de discusión, trabajando en este caso lo que significan para los niños los términos plaza y parque. La experiencia muestra que los pequeños tienen una visión difusa de los conceptos y trabajan en sus relatos con las categorías grande o pequeño, que aplican en relación con la especie de juego que tienen asignado en un lugar determinado. En cambio, los niños mayores elaboran una muestra más amplia de categorías, distinguiendo además entre: plazuelas, bloques de viviendas y aceras más amplias, que también dan juego para el ocio (Müllauer-Seichter, 2010). 


\section{SimbolizACIÓN DE LUGARES: LUGARES ESTIGMATIZADOS, LUGARES DE ESTÍMULO, STRESS LEVELS}

Se da por sentado que el mundo urbano se centra en un mundo simbólico. Esto conduce a la adopción generalizada de un conjunto de símbolos compartidos, lo que se ve muy claramente en la forma en que los topónimos pueden convertirse en símbolos. Estos representan una parte importante en la comprensión individual de la ciudad, como ya se ha mencionado, con respeto a los mapas cognitivos. Mientras el simbolismo arquitectónico contiene una comunicación no-verbal, el uso figurado de determinados topónimos se distingue del primero teniendo más que ver con una comunicación verbal. Walmsley (1988) escribe al respecto que, en un caso de estudio de Sidney, una gran parte de mujeres de la muestra, al preguntarles por el nombre de su barrio dieron uno diferente, derivado de un directorio de calles de la zona:

Guest y Lee encontraron una clara tendencia a que el consenso sea más alto en áreas de alto estatus. Esto plantea la interesante posibilidad de que el estatus y el uso del lenguaje puedan estar relacionados. Esta posibilidad fue vista por primera vez por Berstein (1988), quien hizo una distinción entre lenguaje formal y lenguaje público. Esta investigación sugirió que la diferencia entre los dos es una función de la capacidad conceptual: "los que usan lenguaje público tienen menos probabilidades de conceptualizar los aspectos estéticos del entorno y, en cambio, están preocupados por la necesidad básica de la vida cotidiana" (p. 67).

En este sentido, se puede decir que el lenguaje hablado tiene un papel importante que influye en la relación que tiene el individuo con el lugar. En esta relación resulta interesante cómo el individuo tiene un sentimiento de unión con el lugar ${ }^{12} \sin$ sentirse en casa o, como dice Walmsley (1988), estos lugares pueden generar un espíritu denominado genius loci (genio del lugar). Al respecto, Norberg-Schulz (1980) define:

"Genius loci" es un concepto romano. De acuerdo con las creencias romanas, cada ser tiene su "Genius", su espíritu guardián. Este espíritu da vida a la gente y a los lugares. Los acompaña desde el nacimiento hasta su muerte y determina su carácter o esencia [...] El "Genius loci" ha permanecido como una realidad viviente durante el curso de la historia, a pesar de no haber sido expresado como tal. Artistas y escritores han encontrado inspiración en el carácter local y han explicado el fenómeno, tanto en el arte como en la vida cotidiana, cuando se han referido al paisaje o a los ambientes urbanos. Por ello Goethe dice: "Es evidente que el ojo está educado por las cosas que ha visto desde su niñez, así los pintores venecianos deben ver todo más claro y con más regocijo que otra gente". (p. 1)

Esto no impide que algunos lugares de la ciudad se interpreten como lugares con estatus $^{13} \sin$ que necesariamente las personas se identifiquen con ellos; de la misma manera, otros enclaves serán interpretados como lugares de estigma ${ }^{14}$. Lo que sí tienen en común es que ambos casos se refieren a lugares de estímulo en alguna parte de la ciudad. Siguiendo esta idea, algunas zonas de la urbe se pueden interpretar como lugares de estrés (Walmsley, 1988, p. 68).

En relación con la Casa de Campo, la investigación se inspira en la idea de stress levels, un concepto elaborado inicialmente por Ley (1974) sobre diferentes zonas de la 
ciudad de Monroe (Philadelphia, USA) que producen una sensación de estrés en la percepción de los entrevistados. Siguiendo a Seamon (1984, p. 175), se puede interpretar algunas zonas de la ciudad como lugares con un determinado estatus (estimulantes, bellos, feos), independientemente de que los individuos lo identifiquen así o no. Al contrario, partes del territorio pueden ser lugares estigmatizados ante los ojos de algunos, como también hay sitios de estímulo. Ley (1974) trabaja sobre este fenómeno en la zona de
Monroe de donde procede el esbozo que vemos a continuación (figura 4). En la investigación realizada sobre el parque de Madrid, en las zonas que muestran altos niveles de estrés se presentan dos problemas concretos: la prostitución y el tráfico (Müllauer-Seichter, 2003). El hecho de que, por alguna condición determinada, el lugar destaque entre el conjunto de la urbe de Madrid es también una ocasión para observar las negociaciones y estrategias que aplican los interesados para hacer uso del terreno (figuras 5 y 6 ).

\section{Figura 4}

Stress levels en Monroe (Philadelphia, USA), según Ley (1974).

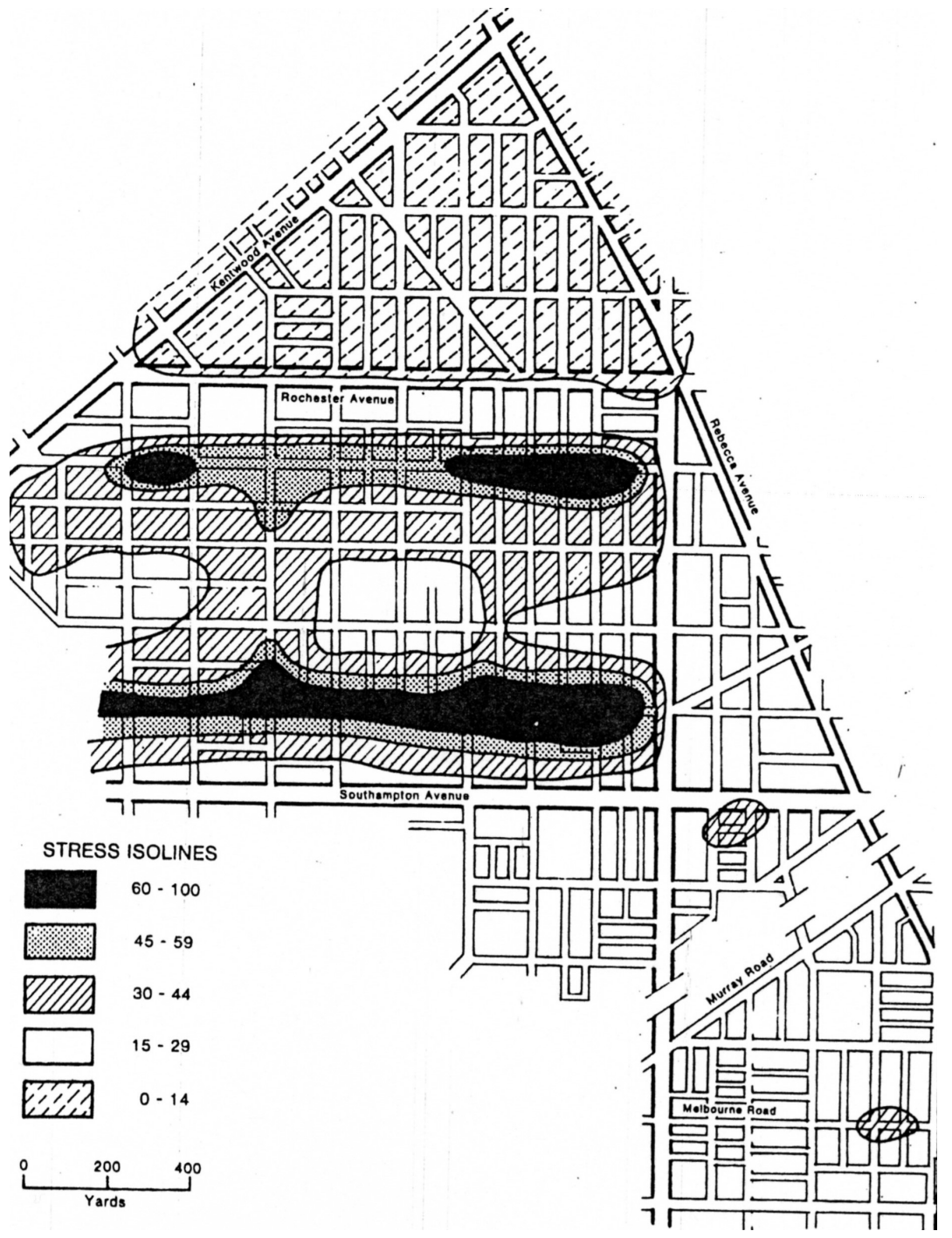

Fuente: Walmsley (1988). 
Figuras 5 y 6

Stress levels en la Casa de Campo:

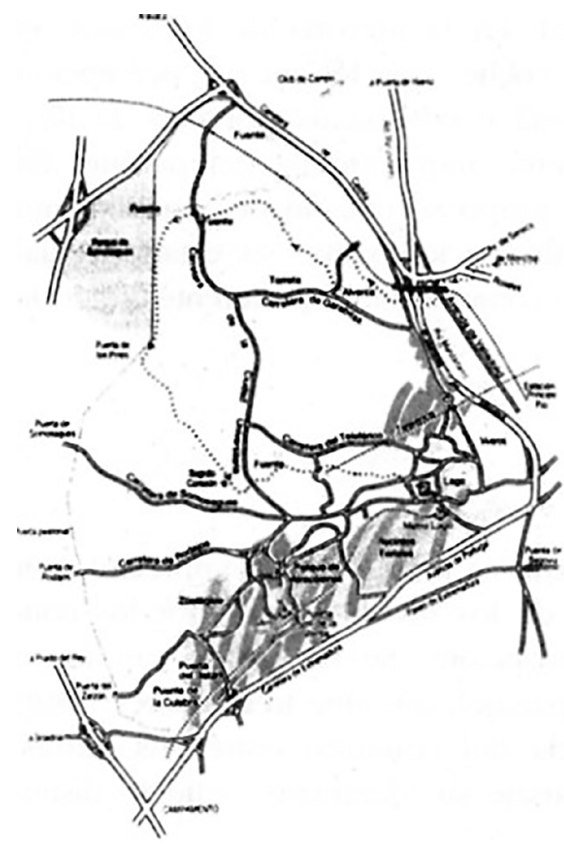

a) Tráfico (durante la semana laboral/ fin de semana).

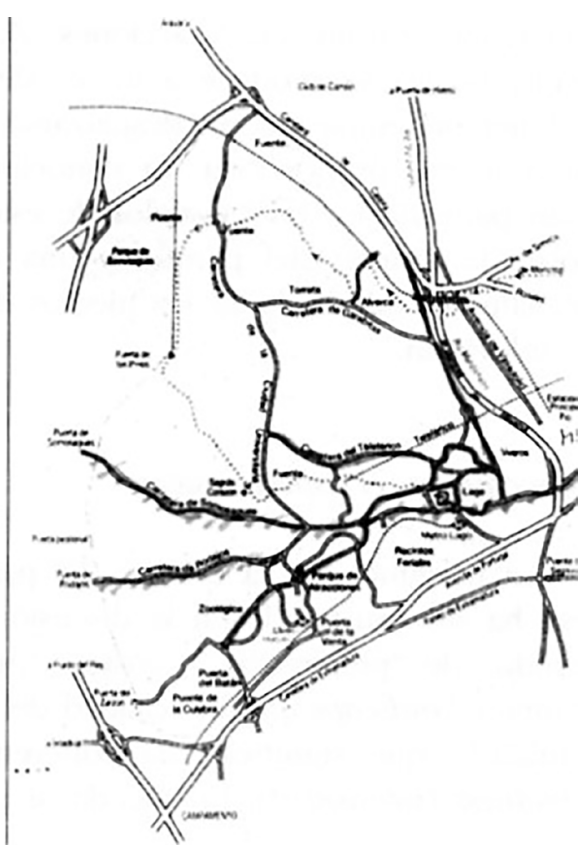

b) Prostitución.

Fuente: W. Müllauer-Seichter (2007).

\section{Otros ASPECTOS DE LA PERCEPCión RELACIONADOS CON EL ESPACIO VERDE URBANO}

\section{Distancia cognitiva, orientación}

Utilizando la terminología de Lynch (1966), explicada anteriormente, una adaptación convincente en el entorno depende de cuatro formas de conocimiento: el conocimiento de nodos (por ejemplo, un lago, una parada de autobús, etc.); el conocimiento de la cercanía de estos nodos en relación con el individuo (desde su casa); el conocimiento entre los diferentes nodos; y, finalmente, el conocimiento del set de nodos (serie de nodos) y su interrelación y conexión, es decir, cómo es su distribución en el área y cómo están interrelacionados los unos con los otros. A primera vista esto parece simple, pero la noción de distancia que la mayoría de la gente tiene en su mente, pocas veces corresponde con una distancia objetiva $\mathrm{y}$, por tanto, no corresponde con frecuencia a la realidad como pudimos comprobar sobre el terreno durante el trabajo de campo en el parque y los barrios de Madrid.

Las investigaciones de Walmsley (1988, p. 29) muestran que, en el caso de distancias relativamente pequeñas, las personas se inclinan a calcular más tiempo del que realmente necesitan para superarlas; mientras que suelen calcular menos en tramos de 
caminos más largos. Esta tendencia no sólo influye a la hora de plantearse movimientos rutinarios, sino también, a la hora de planificar actividades en el tiempo libre. En relación con la investigación, podría significar que muchas veces da más pereza desplazarse un par de horas a la zona verde más cercana que coger el coche e irse a la montaña, que implica el uso de otros recursos y el empleo de muchísimo más tiempo.

Otra observación que se puede comprobar en varias investigaciones es que uno de los primeros aspectos en la interacción entre el individuo y su ambiente es el del atractivo, el aspecto estético (Thompson, 1963). Es decir, los lugares atractivos están considerados generalmente como más próximos que los que ofrecen otro aspecto. Hay diferentes formas de comprobar esta percepción de distancia; en los trabajos presentados se utilizan los mapas cognitivos que esbozan los entrevistados y los paseos urbanos que se elaboran con algunos de ellos.

Entre los tres grupos entrevistados con respeto al parque madrileño, se puede decir que las personas, cuyo vínculo con este lugar se establece a través del empleo, son los que menos relaciones realizan entre los distintos nodos. En alguno de los casos, pueden dar una variedad de accesos para llegar a su sitio de trabajo ubicado en el parque, pero sobre el resto del territorio tienen cierta confusión, aunque existe la posibilidad de relacionar los nodos más espectaculares del mismo (lago, parque de atracciones y zoológico). Para la mayoría de los informantes de este grupo, el acercamiento se produce a través de un vehículo personal, por lo que su percepción del tiempo empleado en desplazarse está condicionada. Además, el desplazamiento en coche proporciona un conoci- miento muy puntual y sesgado del terreno y el parque es un simple lugar de trabajo. Por esta razón, no sorprende que gran parte de los entrevistados de este grupo une un desconocimiento sobre la historia del parque y una desinformación sobre el estado actual de este Sitio Real y un conocimiento plenamente adquirido en los medios de comunicación, preferentemente en la televisión.

\section{El valor del aspecto estético para el observador.}

La pregunta por la estética del paisaje es muy difusa e imprecisa, por eso fue sustituida en el debate de los investigadores por los conceptos de preferencia, gusto y percepción. De hecho, el aspecto estético que abunda en la descripción de parques y jardines, hasta hace muy poco tiempo, no tenía relación con lo social, como la calidad de vida que percibe la gente usándolos. En relación con la inquietud de saber más sobre las percepciones de los usuarios se ha creado el nuevo término de landscape quality (calidad del paisaje). Este término está uniendo tres factores relevantes: unity (unidad), que significa una coherencia del conjunto entre sus partes; vividness (intensidad), lo que da al paisaje su personalidad y lo distingue de otras zonas; y variety (variedad), que implica una complejidad visual (Walmsley, 1988, p. 72).

\section{Apreciación estética según la pertenencia social.}

Generalmente, tanto en lo que se refiere a los espacios verdes, parques y jardines de la urbe como a la arquitectura de la ciudad en su conjunto, habrá que distinguir entre el gusto de la élite (que se plasma en la pintura 
y literatura) y un gusto más popular (gusto público), que se vive y expresa en la vida cotidiana. Mientras que el primero está relacionado con el poder y las historias oficiales de los reinos y gobiernos que se expresan en la ordenación de jardines (de estilo francés), el segundo se refiere a la percepción de la ciudadanía. Se remonta al pasado en la vida individual o de historias familiares, a la infancia, cuando normalmente no existía responsabilidad, pero sí disfrute, lo que provoca sentimientos como continuidad, duración e identidad. A veces esta percep- ción individual no está ni siquiera relacionada con belleza ya que son, precisamente, paisajes feos que cobran sentido personal y constituyen espacios de seguridad por conocerlos y haber pasado en ellos una infancia feliz. Individuos que, por alguna razón han sido desprovistos de sus propias formas de percepción del paisaje en el pasado (prisioneros, exiliados, etc.), suelen tener serios problemas a la hora de actuar con responsabilidad hacia su ambiente por estar guiados plenamente por la noción de funcionalidad.

\section{REFLEXIONES FINALES SOBRE LA APLICACIÓN DE LAS HERRAMIENTAS EN EL TRABAJO DE CAMPO EMPÍRICO: LUCES Y SOMBRAS}

Las investigaciones aquí presentadas que tratan sobre el espacio verde, el espacio público urbano, el alcance de la participación ciudadana respecto a la toma de decisiones sobre el entorno vital y, finalmente, sobre el derecho legítimo de la opinión de los niños dentro de la modificación de espacios lúdicos, son el abanico de unidades de investigación para ver la operatividad de las técnicas. Se trata de estudios realizados a lo largo de los últimos veinte años en diferentes ámbitos geográficos en Europa y América Latina y, también, en diferentes configuraciones sociales, igualitarias y segmentadas. Todos estos componentes entran en cuestión a la hora de acertar en la combinación adecuada de técnicas y herramientas para contestar al objeto de estudio con más eficacia si cabe, superando de esta manera el método convencional de nuestras disciplinas y aprovechando conceptos epistemológicos de campos afines.

Las hojas de frecuencia son una herramienta destacada. A lo largo de este texto se pudo mostrar que su utilización permite recopilar una primera información sobre la unidad que se pretende investigar. En su elaboración no solo se adquieren datos empíricos sobre el uso del espacio en cuestión, además, el investigador toma contacto personal con su unidad de estudio a través de la observación participante, que es de gran importancia para definir de allí en adelante la hipótesis inicial de su estudio. Otra herramienta imprescindible es la elaboración de mapas cognitivos. Como se ve a través de las investigaciones presentadas, la combinación de las técnicas de entrevista semiestructurada y la elaboración de mapas cognitivos con un grupo reducido de entrevistados genera resultados interesantes. La inclusión de personas de edad avanzada en este conjunto permite trabajar la profundidad de memoria individual, la cual incorpora en estos esbozos elementos que ya no existen, pero organizan mentalmente el espacio de la persona, siendo un aspecto interesante que se muestra en el estudio sobre la Casa de Campo. En relación con esta técnica, además, se aplica 
la herramienta de los paseos urbanos para profundizar y concretar este estudio, dando excelentes resultados a pesar del enorme lapso que requiere.

Finalmente, se llama la atención sobre la herramienta de visibilizar los lugares de estímulo, lugares estigmatizados y el trabajo con stress level. En el estudio sobre la Casa de Campo se muestra un terreno con una situación particular para comprobar también, cómo un área de diversión múltiple a la vez está estigmatizada por la prostitución, lo cual afecta a las usuarias en su manera de moverse en ese lugar. Fue interesante analizar qué estrategias desarrollan las mujeres y qué negociaciones son necesarias para acceder a una buena calidad de vida relacionada con el movimiento al aire libre bajo estas circunstancias. La estigmatización del lugar condiciona a los que se mueven en él y, aunque uno intenta declarar su propia condición de manera clara para los demás, a veces el estigma del lugar es tan fuerte, que prácticamente lleva a la renuncia de uso para evitar situaciones ambiguas.

\section{Notas}

1. gradecimientos a María Teresa Riquelme Quiñonero y Matilde Fernández Montes por sus comentarios respecto a este texto.

2. En el ámbito alemán se distingue entre Volkskunde y Völkerkunde. Mientras la Volkskunde se centra en los problemas del propio país y el continente europeo, la Völkerkunde indaga sobre la forma original de vida y fenómenos sociales de comunidades indígenas fuera de Europa.

3. El concepto de Lebenswelt fue creado por Edmund Husserl y alude a todos los actos culturales, sociales e individuales que la vida humana no puede eludir.

4. Una de las últimas intervenciones importantes en la infraestructura de tráfico de Linz (Austria) fue el recinto de la autopista de la ciudad en Bindermichl/Spallerhof.

5. El Taller de Investigación de la Facultad de Arquitectura de la PUCP está dirigido por el profesor Dr. arquitecto Wiley Ludeña Urquizo desde el año 2010.

6. El tema del tiempo libre o tiempo de ocio dentro de las Ciencias Sociales es muy sugerente, destacando su tratamiento en el libro de Tokarski y Schmitz-Scherzer (1985), por la dimensión histórica que aporta del tema; y en el trabajo de Murillo (1996), por su dimensión de género.

7. Eigenlogik, una especie de sociología de cada urbe: estructura espacial, social y emocional, como discuten Berking y Löw (2008) en su trabajo sobre similitudes entre las ciudades de Alemania y Austria.

8. Kuschnir (2016) analiza los trabajos de Malinowski, Barthes, Levi-Strauss, Leach, Meyer Frotes, Wagner y otros.

9. Para profundizar más sobre este tema se recomienda la lectura de los trabajos de W. Müllauer (2002a; 2002b; 2003; 2004a; 2004b). 
10. El Metropolitano es un proyecto de transporte desarrollado por la Municipalidad de Lima. Su construcción ha sido marcada por las incontables postergaciones de entrega (lleva más de 4 años) y el aumento del presupuesto de 190 millones de dólares a cerca de 300 millones de dólares. Fuente: E1 Metropolitano de Lima, publicado en El Comercio el 16 de agosto de 2012.

11. Véanse los trabajos de W. Müllauer (2013a; 2014). Müllauer-Seichter

12. En su trabajo original, el término que utiliza Walmsley (1988) es sense of place.

13. Hace referencia a los parques, plazas, sitios de ocio, etc.

14. Puntos de venta de droga, barriadas, etc.

\section{REFERENCIAS}

Bailly, A. S. (1979). La percepción del espacio urbano. Madrid: Instituto de Estudios de Administración Local.

Berking, H y Löw, M. (2008). Eigenlogik der Städte. Neue Wege für die Stadtforschung. Frankfurt: Campus Verlag.

Bosque-Sendra, J., Castro-Aguirre, C., de, Díaz-Muñoz, M. A. y Escobar-Martínez, F. J. (1992). Prácticas de Geografía de la Percepción y la Actividad Cotidiana. Barcelona: Oikos-Tau.

Gould, P. (1966). On mental maps. Michigan: Inter-University.

Hudson, P. y Pocock, D. (1978). Focal Problems in Geography: Images of the Urban Environment. London: Macmillan Press Ltd.

Jacobs, J. (1973). Muerte y vida de las grandes ciudades. Madrid: Ediciones Península.

Joseph, I. (1999). Erving Goffman y la microsociología. Barcelona: Gedisa.

Klengel, R. (2017). Das Zeichnen als feldforscherisches Werkzeug. Anmerkungen zu einer graphischen Athropologie. Kuckuck, 2, 12-16.

Kuschnir, K. (2016). Ethnographic Drawing: eleven benefits of using a sketchbook for fieldwork, Visual Ethnography, 5(1), 103-134.

Laister, J. y Hieslmair, M. (2013). Relationale Ethnografie: Feldbeziehungen zwischen Kunst, Architektur und Anthropologie. En S. Hess, J. Moser y M. Schwertl (eds.), Europäisch-ethnologisches Forschen. Neue Methoden und Konzepte. Berlin: Reimer Verlag.

Ley, D. (1974). The Black Inner City as Frontier Outpost: Images and Behavior of a Philadelphia Neighbourhood. Washington: Association of American Geographers. 
Lynch, K. (1966). La imagen de la ciudad. Buenos Aires: Infinito.

Lynch, K. (1985). La buena forma de la ciudad. Barcelona: Gustavo Gili.

Müllauer-Seichter, W. (2002a). Segregación del espacio público verde urbano según un análisis de género. Anales de Instituto de Estudios Madrileños, XLII, 175-195.

Müllauer-Seichter, W. (2002b). El impacto de la inmigración en torno al Verde Social: el papel del parque urbano como lugar de encuentro social. En Actas del VI Congreso de la Sociedad Española de Antropología Aplicada (pp. 160-171). Granada.

Müllauer-Seichter, W. (2003). ¿Qué es el parque? Territorio físico e interpretación según la memoria colectiva. ZAINAK, 23, 529-544.

Müllauer-Seichter, W. (2004a). Segregación del espacio público urbano: Territorio público versus interés privados: un análisis de usos en la Casa de Campo de Madrid. Anales de Instituto de Estudios Madrileños, XLIV, 585-611.

Müllauer-Seichter, W. (2004b). Estrategias del uso espacial: El caso de los pequeños enclaves individualizados en la Casa de Campo. En C. Ortiz García (coord.), La ciudad es para ti (pp. 147-264). Barcelona: Anthropos.

Müllauer-Seichter, W. (2010). Hablan los niños: evaluación crítica de plazas y espacios verdes. La opinión experta de niños de Lavapiés para reformar su espacio vital. En M. del Olmo (coord.), Dilemas éticos en antropología. Las entretelas del trabajo de campo etnográfico. Madrid: Trotta.

Müllauer-Seichter, W. (2013a). El "Verde Social” de Lima: formas de participación ciudadana y niveles de desigualdad. El caso de Barranco. Zainak, 36, 107-122.

Müllauer-Seichter, W. (2013b). Niños y ciudad - niños de la ciudad: La “opinión experta" de niños sobre el Verde Social: el missing link. Espacio, sociedad y territorio, 1, 1-33.

Müllauer-Seichter, W. (2014). El precio del progreso... y quien lo paga. Participación ciudadana y toma de decisión en el diseño urbano del espacio público. El caso del Metropolitano, Lima, Perú. En Actas del XIII Congreso de Antropología de la FAAEE. Periferias, fronteras y diálogos (pp. 3245-3262). Barcelona: Universitat Rovira i Virgili.

Murillo, S. (1996). El mito de la vida privada. De la entrega al tiempo propio. Madrid: Siglo Veintiuno de España Editores S. A.

Norberg-Schulz, Ch. (1980). Genius loci. El espíritu del lugar. Aproximación a una Fenomenología de la Arquitectura. Morar, 1.

Omahna, M. (2013). Kulturanthropologie und Architektur. Episteme temporärer Begegnungen. En J. Rolshoven y M. Omahna (eds.), Reziproke Räume. Texte zu Kulturanthropologie und Architektur (pp. 40-49). Marburg: Jonas Verlag.

Seamon, D. (1984). Philosophical directions in behavioural geography with an emphasis on the phenomenological contribution. En T. F. Saarinen (ed.), Environmental Perception a Behaviour: An Inventory and Prospect. Chicago: Research Paper.

Thompson, D. L. (1963). New concept: subjective distance. Journal of Retailing 39, 1-6. 
Tokarski, W. y Schmitz-Scherzer, R. (1985). Freizeit. Stuttgart: Teubner Studienskripten.

Walmsley, D. J. (1988). Urban Living. The Individual in the City. New York: Wiley. 